\title{
APLICACIÓN DE LA EXCEPCIÓN DE INCONSTITUCIONALIDAD EN COLOMBIA. ESTUDIO DE CASO EN EL TRIBUNAL SUPERIOR DEL DISTRITO JUDICIAL DE SAN GIL, 1991-2011 *
}

\author{
Application of the exception of unconstitutionality in Colombia. \\ A case study from the San Gil Higher Court, 1991-2011
}

Daniel Fabián Torres Bayona**, Sergio Andrés Caballero Palomino***
Mariel Viviana Moreno Ortiz ${ }^{* * * *}$, Liseth Katherine Vásquez Gualdrón*****

Recepción: 23 de julio de 2020. Aceptación: 25 de enero de 2021

DOI: http:/ /dx.doi.org/10.21017/Rev.Repub.2021.v30.a104

* Artículo inédito. Resultado del proyecto de investigación «Aplicación de la excepción de inconstitucionalidad en Colombia: estudio de caso del Tribunal Superior del Distrito Judicial de San Gil, entre los años 1991 y 2011», dirigido por Daniel Fabián Torres Bayona, financiado por la Universidad Libre Seccional Socorro, durante los años 2012 a 2014.

** Investigador principal. Doctorando en Derecho, Universidad Autónoma de Barcelona; magister en Derecho con énfasis en Derecho Público, Universidad Externado de Colombia; especialista en Derecho Público, Universidad Autónoma de Bucaramanga; Abogado, Universidad Industrial de Santander. Profesor cátedra Universidad Industrial de Santander. Investigador externo Corporación Universitaria Remington. Miembro del Colectivo Nacional de Abogados. Correo electrónico: dtorresbayona@gmail.com y danfator@correo.uis.edu.co. ORCID: https://orcid.org/0000-0003-1297-9482.

*** Monitor de investigación del proyecto. Magister en Derecho del Estado con énfasis en Derecho Público, Universidad Externado de Colombia; especialista en Derecho Administrativo, Universidad Libre Seccional Barranquilla; abogado, Universidad Libre Seccional Socorro. Profesor investigador y coordinador de investigaciones de la Corporación Universitaria Remington -Uniremington- sede Bogotá. Profesor investigador Corporación Universitaria de Ciencia y Desarrollo -Uniciencia-. Profesor del Colectivo Nacional de Abogados. Correo electrónico: sergio.caballero@uniremington.edu.co. . ORCID https://orcid.org/0000-0003-4715-8537.

**** Auxiliar de investigación del proyecto. Magister en Derecho Administrativo, especialista en Derecho Constitucional y abogada, Universidad Libre Seccional Socorro. Comisaria de Familia de Aratoca, Santander. Correo electrónico: vivianamoreno021091@outlook.es. ORCID: https://orcid.org/0000-0002-5171-0673.

***** Auxiliar de investigación del proyecto. Especialista en Derecho Constitucional y abogada, Universidad Libre Seccional Socorro. Empleada judicial. Correo electrónico: lisita0308@hotmail.com. ORCID: https:/ / orcid.org/0000-0003-4849-7450 


\section{RESUMEN}

En Colombia existe un modelo mixto de control judicial de la constitucionalidad. Por una parte, es concentrado y abstracto en cabeza de la Corte Constitucional y residualmente en el Consejo de Estado y por otro lado es difuso y concreto. Dentro de este pueden evidenciarse la acción de tutela para la defensa de los derechos fundamentales y la excepción de inconstitucionalidad, la cual permite dejar sin efecto una norma jurídica frente a un caso en concreto, cuando esta sea contraria a las normas constitucionales, para así darle cumplimiento al principio de supremacía constitucional. Puede ser solicitada a petición de parte o aplicada de oficio por el juez que conoce del caso.

El presente artículo se centra en estudiar la aplicación e interpretación de la excepción de inconstitucionalidad, circunscrita al Tribunal Superior del Distrito Judicial de San Gil. Así, se busca especificar las áreas del derecho y los eventos en los cuales se ha aplicado en la Salas Civil-Familia-Laboral y Penal de dicho Tribunal, en el período comprendido entre 1991 y 2011, es decir, los primeros 20 años de vigencia de la Constitución Política. De tal manera que se pueda comprobar, en un Tribunal específico, si los jueces conocen y aplican esta modalidad de control de constitucionalidad.

La aplicación de la excepción de inconstitucionalidad garantiza la consolidación del Estado social de derecho y permite que una disposición normativa inconstitucional, sea inaplicada en un caso concreto. Sin embargo, tal modalidad de control es escasamente utilizada por los operadores de justicia, lo cual no ayuda en la consolidación de una cultura constitucional de los jueces. El presente artículo pretende hacer un análisis de la excepción de inconstitucionalidad en Colombia, utilizando en el desarrollo de la metodología un enfoque jurídico, con un tipo de investigación descriptiva y exploratoria, utilizando el método deductivo y analítico.

Palabras clave: Supremacía constitucional, Estado social de derecho, control judicial de constitucionalidad, control difuso de constitucionalidad, excepción de inconstitucionalidad.

\section{ABSTRACT}

The exception of unconstitutionality can rescind a rule of law against a particular case, when this is contrary to the constitutional rules, in order to give effect to the principle of constitutional supremacy.

In this vein the present research focuses on the areas of law Specify and events in which youhave applied the exception of unconstitutionality in the Superior 
Court of San Gil Judicial District, Civil Division, Occupational and Family, in the period 1991-2011, so that you can check whether or not the judges implement this constitutional concept.

A good time was obtained as a result, it only made ??mention of this figure three times in the Labor room, once in the Civil hall and was never mentioned in the family room, without losing sight of that in all situations factual was requested only by the conflicting parties, allowing us to conclude that the judicial goes unnoticed the exception of unconstitutionality, a figure ineffective against officials resolved, so that the Constitution being «supreme law» in a social state law is irrelevant.

Keywords: Supremacy constitutionality, social state, judicial review, fuzzy control, exception of unconstitutionality.

\section{INTRODUCCIÓN}

La excepción de inconstitucionalidad es una de las subespecies del control difuso y concreto de constitucionalidad que hacen parte del control judicial de la Ley que existe en el sistema de justicia constitucional colombiano. Se puede decir que es un remedio procesal creado, para que, mediante la invocación de la Constitución Política, una persona pueda conjurar el riesgo inminente cuando en un asunto de su interés, aprecie que una norma que se va a aplicar a su caso contraría las normas constitucionales $\mathrm{y}$, por tanto, espera que el resultado sea la inaplicación de esa norma a ese caso en particular.

La excepción de inconstitucionalidad tiene su fundamento jurídico en el artículo 4 de la Constitución Política que establece: «La Constitución es norma de norma de normas. En todo caso de incompatibilidad entre la Constitución y la Ley u otra norma jurídica, se aplicarán las disposiciones Constitucionales». Esta norma hace que el sistema de control de constitucionalidad sea calificado por la jurisprudencia y la doctrina como un sistema mixto. Es decir, está compuesto por un control concentrado y abstracto ejercido por la Corte Constitucional y residualmente por el Consejo de Estado y un control difuso y concreto de constitucionalidad en cabeza de cualquier autoridad judicial para que en un caso en particular pueda dejar de aplicar la Ley u otra norma jurídica por ser contraria a la Constitución. Es importante manifestar que esta modalidad de control se puede solicitar de oficio por el juez o Tribunal encargado del asunto o a petición de parte interesada en las resultas de ese proceso. En razón a ello, en el evento en que la norma legal o disposición reglamentaria se haya exceptuado por inconstitucional, esta no desaparece 
del ordenamiento jurídico; debido a que este control solo tiene efectos inter partes, se aplica únicamente para el caso en concreto y no anula la norma por ser contraria a la Constitución.

La excepción de constitucionalidad como parte del control de constitucionalidad fue creada con el fin de garantizar que el ordenamiento jurídico colombiano esté ajustado al Estado social y democrático de derecho y a la supremacía constitucional. Por ello su creación se produjo con el propósito de salvaguardar los postulados constitucionales de supremacía de la Constitución y así impedir que ese poder exorbitante sea colocado al servicio de intereses diferentes de los de la comunidad. Vladimiro NARANJO MEZA señala que «La excepción no es más que una razón. Pero es una razón de la discusión distinta de la defensa» (1994, pp. 170-171). En otras palabras, la frase no es más que un giro retórico orientado a subrayar la supremacía constitucional. Por consiguiente, no se plantea como una garantía fundamental ciudadana en la forma de excepción.

Lo que es indiscutible es que la razón fundamental para considerar y divulgar que la excepción de inconstitucionalidad es tal, es decir una excepción, procesalmente hablando, es la de que ella corresponde plenamente a la primera y más amplia de las acepciones del término, que es la de ser un medio de defensa. Ahora bien, manifiesta Juan Manuel CHARRY URUEÑA «que el término tradicional de excepción no es apropiado, que la denominación correcta debería ser aplicación preferencial de la Constitución» (1994, pp. 164-165). Así pues, el asunto está claro: en cualquier dilema de aplicación de una norma jurídica que sea contraria a la Constitución en el marco de un proceso judicial, el juez o Tribunal a cargo de resolver el asunto, cualquiera que sea, está en la obligación jurídica, por mandato directo de la Constitución Política, de preferir las disposiciones de esta por encima de las normas infra constitucionales.

En el caso específico de la aplicación e interpretación de la excepción de inconstitucionalidad por el Tribunal Superior del Distrito Judicial de San Gil, se ha evidenciado que las sentencias no se fundamentan en rigor al principio de supremacía constitucional, sino que, por el contrario, se direccionan en su generalidad al principio de legalidad. En razón a ello se puede observar que los operadores judiciales en la resolución de sus providencias siguen la corriente legalista, perdiendo de vista el ideal principal de un Estado social y democrático de derecho. Siendo el Tribunal Superior del Distrito Judicial de San Gil, uno de los organismos judiciales encargados de impartir justicia en Colombia, se seleccionó para aplicar la investigación, buscando establecer una muestra que confirme la aplicación o inaplicación de la excepción en los casos resueltos por este Tribunal. 


\section{JUSTIFICACIÓN}

Dentro del constitucionalismo colombiano se plantean varios escenarios para realizar el control de constitucionalidad, siendo uno de estos la excepción de inconstitucionalidad, la cual busca amparar el principio de supremacía constitucional. En este orden de ideas, es posible afirmar que la investigación propuesta es relevante, pues los resultados y los productos obtenidos de la misma, se direccionan a consolidar el criterio axiológico enunciado, permitiendo a las partes en conflicto tener un convencimiento pleno que la resolución del caso específico garantizará la seguridad jurídica.

A su vez, entrar a explorar un campo virgen en investigación respecto al tema planteado, como lo son las sentencias proferidas por el Tribunal Superior del Distrito Judicial de San Gil, hace que la investigación sea pertinente y objetiva, pues dará cuenta si la posición que uno de los organismos encargados de dirimir los conflictos en Colombia, se ajusta a los mandatos constitucionales, al aplicar o no la excepción de inconstitucionalidad en las diferentes áreas del Derecho, teniendo como base un conjunto de fallos actuales, edificados bajo el Estado social de Derecho propuesto por la Constitución Política de 1991.

Además, la investigación permite que la comunidad académica y jurídica, en especial sus estudiantes, puedan crear conocimientos susceptibles de verificación a través del estudio del caso planteado. Teniendo así un punto de vista crítico de la realidad judicial en que se encuentra no solo en San Gil, sino en general en la comunidad, siendo el Tribunal Superior del Distrito Judicial, uno de los organismos jerárquicos más importantes del ente territorial en la Rama Judicial. Tal vez sea esta perspectiva la que manejan los demás operadores judiciales en Colombia.

\section{PROBLEMA DE INVESTIGACIÓN}

La pregunta problema que orientará el desarrollo de este artículo, producto de la investigación realizada es ¿cómo ha sido la aplicación e interpretación de la excepción de inconstitucionalidad en el Tribunal Superior del Distrito Judicial de San Gil, en el período 1991-2011?

Por tanto, el objetivo general propuesto, no puede ser otro que especificar los eventos de aplicación e interpretación de la excepción de inconstitucionalidad en el Tribunal Superior del Distrito Judicial de San Gil, en el período 19912011. Para cumplir tal fin, los objetivos específicos son los siguientes: 1) seleccionar las Sentencias en las cuales se ha hecho mención de la excepción de inconstitucionalidad, ora sea haya aplicado, ora inaplicado, de oficio o a peti- 
ción de parte; 2) describir las áreas del derecho, los eventos y los motivos por los cuales se ha aplicado o inaplicado la excepción de inconstitucionalidad; y 3) construir un cuadro matriz donde se clasifiquen las áreas del derecho, los eventos y motivos en las Sentencias en las cuales se hizo mención a la excepción de inconstitucionalidad, háyase aplicado o no.

\section{ESTRATEGIA METODOLÓGICA}

La presente investigación es de forma aplicada, socio-jurídica, por cuanto se estudiará, no el carácter dogmático del Derecho, sino los fenómenos que se pueden apreciar en la realidad, teniendo en cuenta que el objeto del proyecto es la aplicación del instituto jurídico de la excepción de inconstitucionalidad con la finalidad de determinar su eficacia como norma valoradora de las relaciones sociales.

Esta investigación propone un enfoque cualitativo. En primera medida se determinarán el número de sentencias proferidas por el Tribunal Superior del Distrito Judicial de San Gil, en el período 1991 a 2011. Seguidamente se extraerán las sentencias donde se menciona la excepción y en las cuales se aplica o inaplica. Finalmente se realizará un análisis sobre los motivos y eventos que obligaron a la parte a solicitarla o por su parte al juez a invocarla de oficio.

El estudio será de tipo práctico o de campo. Se recopilará información sobre la aplicación o inaplicación de la excepción de inconstitucionalidad en el Tribunal Superior del Distrito Judicial de San Gil, en el período 1991 a 2011, la cual se tabulará y analizará. Se observará la población objeto de estudio; esto es, las sentencias proferidas por el órgano judicial mencionado en el período indicado.

\section{RESULTADOS}

\section{Orígenes del control difuso de constitucionalidad en Colombia, 1910- 1991}

El control difuso de constitucionalidad, como modelo de control judicial, inicia en el sistema jurídico estadounidense, citándose como precedente el caso MARBURY contra MADISON del año 1803. El juez Marshall inaplica una Ley federal por considerarla contraria a la Constitución de los Estados Unidos, si bien existen casos anteriores de aplicación directa de la Constitución a casos concretos, como lo señala GRANT (1963). Esta modalidad de control se fundamenta en otorgar a todos los jueces la facultad de acudir a la Constitución en 
forma directa y abstenerse de aplicar una norma legal cuando la consideran incompatible o contraria con aquella. TOBO RODRÍGUEZ (2006) señala que el "control difuso se caracteriza por la posibilidad de que diferentes órganos del Estado se encuentren facultados, por igual, para declarar la inconstitucionalidad de una norma».

No obstante, este control opera al momento de dar solución a casos concretos, los cuales producen efectos inter partes. En el sistema judicial estadounidense cobran importancia las decisiones proferidas con anterioridad, dándose aplicación al principio del stare decisis, mediante el cual el juez queda vinculado por su propio precedente y por el precedente contenido en los fallos de los jueces o Tribunales superiores, «observar lo que se ha decidido». Sin embargo, un juez puede alejarse de un precedente judicial, utilizando unas técnicas que en la práctica han cobrado importancia: distinguishing, reversing y overruling. Es importante aclarar, que cuando una inconstitucionalidad es declarada por la Suprema Corte de los Estados Unidos, sus efectos jurídicos son erga omnes, todos los demás jueces deben seguir este precedente, y este no puede ser desconocido.

Los primeros intentos por crear instrumentos jurídicos capaces de salvaguardar la supremacía de la Constitución Política fueron incipientes y frágiles, entre otras cosas porque el Estado colombiano fundamentaba su legitimidad en el principio de legalidad, estando así la Ley sujeta a controles políticos, no jurídicos. A raíz de la inseguridad jurídica que caracterizaba el siglo XIX, el camino hacia un constitucionalismo, tomaba claridades momentáneas, pues más que razonamientos hermenéuticos, las ideas de un constitucionalismo se basaban en pasiones e ideologías meramente políticas.

Desde 1811 hasta 1886, la intromisión recíproca de las ramas del poder público en sus funciones jugaba un papel fundamental, al no permitir avanzar en el asentamiento de las corrientes de control constitucional norteamericanas en el sistema jurídico colombiano. La Constitución Política de 1886 junto con la Ley 153 de 1887 son momentos que marcan un avance y posterior retroceso en el marco del constitucionalismo. La Constitución en mención, establece en su artículo 20 una responsabilidad de los funcionarios que aplicarán una Ley contraria a la Constitución. Sin embargo, tan solo un año después de proclamarse, la Ley señalada elimina el artículo referenciado otorgándole a la Ley presunción de constitucionalidad. Los constituyentes colombianos del primer siglo republicano necesitaron depositar la confianza del sistema en alguien distinto a los poderes legislativo y ejecutivo y confiaron en el juez. En el fondo, el contexto socio-político así lo aconsejaba y con ello expresaron su fe en la cultura jurídica como elemento civilizador y pieza necesaria de la cultura política (CHINCHILLA, 2010). 
En Colombia, la excepción de inconstitucionalidad surge a través del Acto Legislativo 03 de 1910, que reformó parcialmente la Constitución de 1886. Allí se aportaron novedades notables al constitucionalismo colombiano. Un primer aporte es la adopción del principio de la supremacía constitucional sin restricción alguna estipulada en el artículo 40. En segunda medida la concepción del juez constitucional, consagrada en el artículo 41. Por último, el sistema de control de constitucionalidad, conformado por dos modalidades: un control concentrado en cabeza de la Corte Suprema a través de la acción pública de inconstitucionalidad y un control difuso ejercido por medio de la excepción de inconstitucionalidad, permitiendo darle características propias a dichas institucionales que aún están vigentes. ZAMBRANO (2011, pp. 120-121) refiriéndose al Acto Legislativo 3 de 1910, señala:

La excepción de inconstitucionalidad consagrada en este acto legislativo fue muy criticada en sus comienzos; sus opositores consideraban dicha figura de excepción como un atentado directo y profundo contra la separación de poderes mientras se otorgaban alcances y prerrogativas especiales al poder judicial (...) perspectiva errónea ya que dicho control se convertiría con el tiempo en una alternativa de defensa ciudadana frente a los abusos del legislador, como ejercicio de una democracia participativa y de alcance popular. Además, debe pensarse que tal control no constituye peligro, puesto que la excepción responde a una decisión coherente y competente de cualquier operador jurídico conforme a los valores judiciales de Derecho. No obstante, adviértase que también el debate público y abierto empezaba a ser epicentro de reuniones por parte del poder legislativo.

Se puede deducir del estudio de los artículos 40 y 41 del Acto Legislativo 03 de 1910 que su objetivo fue dejar claro que las normas de un sistema jurídico están organizadas jerárquicamente, con la Constitución en la cúspide, y que el control de constitucionalidad es una institución jurídica que garantiza dicha organización del sistema de fuentes, así sea uno mixto. María José MAYA (2012) afirma que el control por vía de excepción fue la respuesta de los liberales y de los conservadores históricos, que se unieron en el Partido Republicano al presidencialismo excesivo plasmado en la Constitución de 1886, al veto permanente del ejercicio de la libertad de prensa, a la exclusión de la minoría y a la discordia entre los partidos mayoritario y minoritario. Estos sistemas de control, fueron a su vez consecuencias del abuso de poder por parte del legislativo, reiterando el debilitamiento del Parlamento y la fuerza del Poder Judicial, introduciendo un sistema de control que se iniciaba tanto por vía de acción como de excepción.

La Corte Suprema de Justicia en Sentencia de la Sala Plena del 3 de noviembre de 1911, empieza a aplicar la excepción de inconstitucionalidad que un año 
antes se había consagrado en el artículo 40 del Acto Legislativo nro. 3. Los términos en los cuales se expresa la Corte para sustentar la inaplicabilidad de la Ley y explicar el caso son los siguientes:

De igual modo que la expresada Comisión del Senado, el señor Procurador General es de concepto que las objeciones aducidas por el señor Presidente de la República deben tenerse por infundadas mientras subsista la facultad que otorga al Congreso la precitada Ley 18 de 1890. Con todo, semejante doctrina, que fue jurídicamente correcta y de estricta observancia hasta ayer no más, en fuerza del derogado artículo $6^{\circ}$ de la Ley 153 de 1887, es de todo punto inaceptable en la actualidad, porque ella está en abierta contradicción con el principio fundamental consignado en el artículo 40 del Acto Legislativo número 3 de 1910, que manda aplicar de preferencia las disposiciones constitucionales en todo caso de incompatibilidad entre la Constitución y la ley. Por lo demás, conviene advertir que para las objeciones a que se alude no se ha invocado la simple ilegalidad del proyecto mencionado, sino su repugnancia con un precepto constitucional, en uno de los dos casos en que al Presidente de la República le está permitido oponer su veto a los proyectos de leyes adoptados por el Congreso y sometidos a la sanción del Poder Ejecutivo; de donde claramente se deduce que el punto que se discute ha de ser estudiado y decidido a la sola luz de la Carta Fundamental, y haciendo abstracción completa de las leyes ordinarias discordantes con ella, una vez que estas no pueden prevalecer en manera alguna sobre aquella, sin que lógicamente resulte poco menos que ilusoria la atribución presidencial conferida a este respecto (MORENO, 2010, p. 87)

Al final del segundo gobierno de Alfonso López Pumarejo, se reforma la Constitución Política de 1886 a través del Acto Legislativo 1 del 16 de febrero de 1945. En el artículo 53 de esa reforma, se reitera la competencia de la Corte Suprema de Justicia para salvaguardar la supremacía constitucional. Así mismo, el artículo 54 modifica el artículo 148 constitucional, reafirmado la importancia del control difuso pues señala: «En todo caso de incompatibilidad entre la Constitución y la Ley, se aplicarán de preferencia las disposiciones constitucionales» RESTREPO (2005, p. 517).

\section{La excepción de inconstitucionalidad en la Constitución de 1991}

La Constitución Política de 1991 creó en su artículo 239 la Corte Constitucional y el artículo 241señaló que a ella «... se le confía la guarda de la integridad y supremacía de la Constitución». En el artículo 237.2 de la Constitución se señala que el Consejo de Estado tiene competencia para conocer las demandas de nulidad por inconstitucionalidad, encaminadas a que se realice un control de constitucionalidad de los Decretos dictados por el Gobierno Nacional, cuya 
competencia no corresponde a la Corte Constitucional, es decir, los Decretos Ordinarios y Reglamentarios, pues la inconstitucionalidad de los Decretos Ley y de los Decretos Legislativos debe ser declarada por la Corte Constitucional como señala el artículo 241 en sus incisos 5 y 7 respectivamente.

Además, el artículo 4 señaló: «La Constitución es norma de normas. En todo caso de incompatibilidad entre ella y la ley u otra norma jurídica, se aplicarán las disposiciones constitucionales». En esos términos bien se puede entender que tal disposición establece la supremacía constitucional, principio que implica reconocer a la Constitución Política como norma fundamental del Estado, otorgándole categoría de Ley suprema, poniéndola por encima de las demás normas, de las cuales constituye su fuente primaria. Dentro de dicha supremacía, la Constitución se impone como el grado más alto dentro de la jerarquía de las normas, de manera que el contenido de las normas jurídicas está limitado por ella.

Entonces, haciendo un análisis de los artículos 4, 237.2 y 241 el sistema de control judicial de constitucionalidad en Colombia puede ser considerado como mixto, debido a que 1) dos órganos de naturaleza jurisdiccional, esto es, Corte Constitucional y Consejo de Estado, en el ámbito de sus competencias realizan un control concentrado y abstracto, ya que les interesa la confrontación entre una norma constitucional y otra infra constitucional a través del silogismo jurídico y 2) todos los jueces dentro del proceso de aplicación de la Ley en los casos bajo su conocimiento, revisan si su compatibilidad con la Constitución en el caso concreto. Es decir, al ser la supremacía constitucional un principio del cual se desprenden criterios axiológicos e interpretativos y como a la Corte Constitucional se le confía su guarda, indiscutiblemente cualquier funcionario judicial tiene la capacidad para inaplicar una norma jurídica en un caso concreto, cuando considere que es violatoria de la Constitución y ella no ha sido aún declarada inexequible por la Corte Constitucional. Así que el objeto del control difuso no es la anulación, cuestión que es del resorte del control abstracto sino la inaplicación de la norma en el proceso específico. Al contrario de lo que sucede en el control concentrado, la Ley conserva su eficacia jurídica, no se anula, produce efectos interpartes y podría ser aplicada posteriormente a los demás casos, siempre y cuando allí no se genere también una inconstitucionalidad. La Corte Constitucional, por su parte, ha aceptado la existencia y el ejercicio del control difuso en su jurisprudencia:

La Corte Constitucional tiene la capacidad jurídica para declarar la inaplicabilidad, en un caso concreto, de una norma legal, cuando considera que es violatoria de la Constitución y ella no ha sido aún declarada inexequible. En este sistema el proceso ya no es ofensivo: para invocar la inconstitucionalidad de la ley es necesario que ésta haya sido aplicada; es 
decir, que no interviene sino de manera incidental, a propósito de un proceso, y a título de excepción presentada por una de las partes en él. En este caso si el juez encuentra fundada la demanda de inconstitucionalidad, dejará de aplicar la ley, pero únicamente para quien lo solicitó. Al contrario de lo que sucede en la acción de inconstitucionalidad, la ley conserva su eficacia jurídica, es decir, no se anula, y por consiguiente podrá ser aplicada posteriormente, siempre que no se le oponga la excepción de inconstitucionalidad. El objeto de la excepción no es pues la anulación, sino la no aplicación de la ley en el proceso establecido. (Sentencia T-006 de 1994)

También, la doctrina ha aceptado la procedencia del control difuso. Por ejemplo, GIRÓN (2003) conceptualiza esta institución jurídica en los siguientes términos:

El control de constitucionalidad por vía de excepción deriva del artículo 4 $\mathrm{CP}$, que dispone que en caso de incompatibilidad entre la Constitución y la ley u otra norma jurídica, se aplicarán las disposiciones constitucionales. Se trata de una forma de control que puede ser ejercida en Colombia por todas las esferas de la actividad estatal y, por tanto, por cualquier autoridad judicial o funcionario público debe inaplicar aquellas normas jurídicas que estimen contrarias a los preceptos constitucionales en el caso concreto bajo examen, sin necesidad de suscitar ningún incidente ante la Corte Constitucional, con efectos inter partes, esto es, la inaplica en la solución de ese caso específico, pero la norma continúa vigente. No obstante, se ha defendido que la aplicación de esta figura jurídica debe estar restringida a las entidades judiciales, sin embargo, el art. 4 hace referencia a todo aquel que se encuentre encargado de aplicar normas, sin establecer diferencia a este respecto. Por ello, incluso los particulares investidos transitoriamente de la función de administrar justicia en la condición de conciliadores o de árbitros (art. $116 \mathrm{CP}$ ) pueden ejercer este control de constitucionalidad, cumpliendo así con el principio constitucional de supremacía de la Constitución.

$\mathrm{Al}$ respecto, Eduardo CIFUENTES MUÑOZ (2006, p. 70), ex magistrado de la Corte Constitucional colombiana sostiene:

Pese a la centralización de las competencias de control de constitucionalidad más importantes en cabeza de la Corte Constitucional, lo que introduce un factor que estimula su concentración, la posibilidad de que cualquier juez pueda directamente inaplicar la ley que a su juicio sea incompatible con la Constitución (art. $\left.4^{\circ}\right)$, sin necesidad de suscitar ningún incidente ante la Corte Constitucional, refuerza las características de control difuso que siguen estando presentes en el sistema. 


\section{El Estado social de derecho, la supremacía constitucional y el control de constitucionalidad en Colombia}

La Constitución Política de Colombia de 1991 consagró por un lado al Estado como social y democrático de derecho y, por otro lado, la supremacía constitucional. Ello, porque requería dar pasos en la consolidación de una democracia más abierta, plural, y superar el Estado de derecho en donde la principal norma jurídica era la Ley, entendida como la emanación de la voluntad popular emanada del Parlamento. Todo ello con el fin de establecer en la cúspide de la jerarquía normativa una Constitución que no solo fuera formal sino también material; esto es, con fuertes principios y derechos fundamentales que garantizaran su vigencia.

Como señala LANCHEROS (2009, pp. 256-259), para que sea posible un Estado Constitucional se requiere: la existencia de una Constitución Política rígida que consagre un catálogo de valores, principios y derechos fundamentales; la existencia de una garantía jurisdiccional que permita mantener la supremacía constitucional; el reconocimiento de la fuerza vinculante de la Constitución; la interpretación extensiva de la Constitución, es decir, con la forma como ella es utilizada para llenar las lagunas de sus propias disposiciones y del ordenamiento jurídico en general; la aplicación directa de la Constitución, lo cual sin duda, tiene que ver en el contexto colombiano con el control difuso de constitucionalidad; y la interpretación de toda la normatividad conforme a la Constitución. Otro autor, DEL ROSARIO (2011, p. 104), señala:

Hans Kelsen concebía a la Constitución como suprema por ser esta la que fundaba a todo el sistema jurídico. La norma suprema es la que establece cómo se deben crear todas las normas jurídicas del sistema. Para que estas puedan ser vigentes y válidas, deben contener otro requisito también previsto por la Constitución: señalar cuál es el órgano competente para expedirlas.

La Corte Constitucional colombiana a lo largo de sus más de 29 años de funcionamiento le ha dado especial importancia al tema de la supremacía constitucional, pues como lo señala la misma Constitución, a dicho Tribunal se le confía la guarda de su integridad y supremacía. Por ejemplo, en Sentencia C-415 de 2012, señaló:

“La supremacía de la Constitución Política sobre el resto de prescripciones del sistema de derecho nacional, es un principio estructurante del orden jurídico: el conjunto de prescripciones que integran el derecho positivo, se ordena en un sistema normativo, en virtud de la unidad y coherencia que le imprimen los valores, principios y reglas establecidas en la Constitución. 
En otras palabras, el orden jurídico de la sociedad política se estructura a partir de la Carta Fundamental".

El profesor Allan BREWER-CARÍAS (1995) sostiene que el modelo de control jurisdiccional que opera en Colombia es mixto porque contiene elementos tanto del concentrado como del difuso. Por el número de jueces que intervienen en la protección constitucional, el sistema parece ser difuso; pero el hecho de que existe una Corte Constitucional que actúa como Tribunal supremo de constitucionalidad y como máximo intérprete de la Constitución Política, le permite al sistema un control unificado en materia constitucional. El control de constitucionalidad en Colombia, se edificó, a partir de las corrientes europeas y estadounidenses, terminando por concluir en un sistema mixto, pues se acepta la aplicación de los dos sistemas jurídicos de control de constitucionalidad a saber: el difuso y el concentrado.

Mientras tanto, en el otro costado del mundo, Hans KELSEN propone un control concentrado de constitucionalidad, también denominado sistema austríaco o europeo. En palabras de TOBO RODRÍGUEZ (2006) se entiende así: «Se presenta cuando el orden jurídico del estado confiere a un solo órgano la atribución para decidir acerca de la exequibilidad de todas las normas». En tanto, Colombia inicia un proceso de búsqueda de instrumentos que estuvieran al alcance tanto de los ciudadanos, como de los poderes del Estado, para hacer efectiva la Constitución Política, iniciando un camino donde paso a paso se fueron instituyendo medios de defensa del orden público (TORRES BAYONA, 2013, p. 56-57).

Es así como se evidencian los controles de constitucionalidad, cuya teleología, sin lugar a dudas, se fundamenta en la supremacía de la Constitución Política, dando paso así al control concentrado y al control difuso de constitucionalidad. Este control de constitucionalidad tiene su génesis en Europa cuya autoría se debe a Hans KELSEN. A su vez tiene como característica fundamental, la creación de un único órgano superior, que recibe el nombre de Tribunal o Corte Constitucional, cuya función se enmarca en la protección de constitucionalidad de las Leyes y garantizar la supremacía del texto constitucional, otorgándosele así, la facultad para expulsar del ordenamiento jurídico las Leyes inconstitucionales mediante sentencias que tienen efectos erga omnes.

\section{La excepción de inconstitucionalidad en la realidad judicial}

La Corte Constitucional a través de los fallos de tutela ha venido realizando una labor de unificación jurisprudencial de la interpretación constitucional con la adopción del principio de la obligatoriedad del precedente. Para tal efecto ha señalado: 
(...) hay que tener en cuenta que el control por vía de excepción lo puede realizar cualquier juez, autoridad administrativa e incluso particulares que tengan que aplicar una norma jurídica en un caso concreto. Este tipo de control se realiza a solicitud de parte en un proceso judicial o ex officio por parte de la autoridad o el particular al momento de aplicar una norma jurídica que encuentre contraria a la Constitución. En este caso se debe subrayar que la norma legal o reglamentaria que haya sido exceptuada por inconstitucional no desaparece del sistema jurídico y continúa siendo válida ya que los efectos del control por vía de excepción son inter partes, solo se aplican para el caso concreto y no anulan en forma definitiva la norma que se considera contraria a la Constitución. Por este hecho una norma que haya sido exceptuada por cualquier autoridad judicial, administrativa o por un particular cuando tenga que aplicar una norma, puede ser demandada ante la Corte Constitucional que ejercerá el control de constitucionalidad y decidirá en forma definitiva, de manera abstracta, general y con efectos erga omnes si la norma exceptuada es constitucional o no. Teniendo en cuenta lo anterior, considera la Corte que las excepciones de inconstitucionalidad que profieren las autoridades judiciales, administrativas o los particulares cuando tengan que aplicar una ley, no elimina la posibilidad que tiene la corporación de realizar el control de constitucionalidad de determinado precepto" (Sentencia C-122, 2011).

La Corte Constitucional ha proferido decisiones que se direccionan a asegurar que los elementos concentrados del sistema de control constitucional sean respetados. Entre esas providencias se encuentra la sentencia T-669 de 1996, que señaló que los jueces están en la obligación de hacer uso de la excepción de inconstitucionalidad respecto de normas vigentes que reproducen el contenido de disposiciones que ya han sido declaradas inexequibles por la Corte Constitucional. Las razones esgrimidas en la tutela citada coinciden con la necesidad de preservar la supremacía de la Constitución. Dijo la Corte Constitucional que el juez que no cumpliera este deber y, por lo tanto, aplicara la norma contraria a la Constitución incurriría en una vía de hecho:

Por ello, cuando un juez o un fiscal aplican una disposición formalmente vigente pero que tiene el mismo contenido material de una que ya ha sido declarada inexequible por la Corte Constitucional, es indudable que están violando este precepto constitucional, pues están en la práctica reproduciendo «el contenido material del acto declarado inexequible». En tales eventos, el funcionario judicial está obligado a aplicar la excepción de inconstitucionalidad, pues la Constitución es norma de normas (CP art. $\left.4^{\circ}\right)$ $\mathrm{o}$, en caso de que no lo considere pertinente, debe mostrar de manera suficiente que la disposición que, dada la situación del caso concreto, pretende aplicar tiene en realidad un contenido normativo en parte diferente a la 
norma declarada inexequible, por lo cual puede seguirse considerando constitucional. Si el funcionario aplica la norma y no justifica su distanciamiento frente al pronunciamiento previo de la Corte Constitucional sobre el mismo tema, estaríamos en presencia de una vía de hecho, pues el funcionario judicial decide aplicar caprichosamente de preferencia las disposiciones legales a las normas constitucionales, en contravía de expresos pronunciamientos sobre el punto del tribunal constitucional, máximo intérprete y guardián de la Carta (CP arts $4^{\circ}, 241$ y 243) (Auto 071, 2001).

De tal forma, se le concede a jueces y funcionarios investidos de jurisdicción, la excepcional facultad de dejar de aplicar una norma cuando se considere que esta es abiertamente violatoria de la Constitución, siendo precisamente esta disposición la llamada excepción de inconstitucionalidad; objeto central de esta investigación. Actualmente, el Estado colombiano cuenta con figuras jurídicas o controles que cobran relevancia al momento de materializar los derechos fundamentales de sus ciudadanos, dando así aplicación a la esencia de la Constitución Política de 1991, que introdujo en el constitucionalismo nacional cambios importantes, como lo fue la transformación del Estado de derecho al Estado social de derecho.

\section{La excepción de inconstitucionalidad aplicada por los jueces ordinarios. El caso del Tribunal Superior del Distrito Judicial de San Gil}

En la Sala Civil-Laboral-Familia del Tribunal Superior del Distrito Judicial de San Gil, durante el período 1991 a 2011, correspondiente a 20 años, se han emitido 1192 sentencias en procesos civiles, laborales, de familia, agrarios y comerciales. De esta manera las áreas el derecho en las cuales se ha hecho mención de la excepción de inconstitucionalidad corresponden a tres procesos ordinarios laborales y un proceso ejecutivo con título hipotecario; esto quiere decir, tres asuntos en materia laboral y un asunto en materia comercial, casos en los cuales fue solicitada su aplicación por una de las partes, pero negada de oficio por el Tribunal Superior. En las áreas de derecho civil, derecho de familia y derecho agrario no se ha hecho mención de la excepción de inconstitucionalidad, ya que ninguna de las partes de estos procesos lo solicitó y nunca fue aplicado de oficio por el Tribunal Superior. En materia penal nunca se ha aplicado de oficio la excepción de inconstitucionalidad en el período estudiado y ni siquiera ningún sujeto procesal ha solicitado su aplicación.

En tres procesos ordinarios laborales, una de las partes solicitó al Tribunal la aplicación de la excepción de inconstitucionalidad en el respectivo caso. Dichos procesos son los siguientes: Sentencia de fecha 23 de octubre de 2003, con radicado nro. 68-755-31-03-002-2002-0023-01, M.P. Pedro José Rodríguez Uribe; Sentencia de fecha 21 de septiembre del 2006, con radicado nro. 68861-3103- 
002-2004-00065-00, M.P. Carlos Augusto Padilla Tarazona; Sentencia de fecha 2 de noviembre del 2008, con radicado nro. 68-755-31-03-001-2004-00047-01, M.P. Javier González Serrano. Los motivos por los cuales se ha inaplicado la excepción de inconstitucionalidad por parte del Tribunal son los siguientes:

- El artículo 251 del Código Sustantivo del Trabajo violaba el derecho a la igualdad. Se negó con el siguiente argumento: «el artículo 251 del Código Sustantivo del Trabajo dice que el artículo 249 de la misma norma, no se aplica a los artesanos que, trabajando personalmente en su establecimiento, no ocupen más de cinco trabajadores permanentes extraños a su familia».

- Es nula la terminación de los contratos, en razón a que se predica la inconstitucionalidad del Decreto 1615 de 2003. Se negó con el siguiente argumento: «El Decreto demandado tiene plena vigencia y se encuentra revestido de la presunción de legalidad, en atención a que no ha sido declarado nulo por la jurisdicción correspondiente».

- El artículo 1 de la Ley 4 fue derogado por la Ley 100 de 1993, su texto no se ha agotado y continúa produciendo efectos jurídicos. Se negó con el siguiente argumento: «La acusación contra el artículo $1^{\circ}$ de la Ley $4^{\circ}$ de 1976 se estructuró a partir de un supuesto equivocado toda vez que dicha norma, además de encostrarse derogada tácitamente por el artículo $1^{\circ}$ de la Ley 71 de 1998, en la actualidad no está produciendo ningún efecto jurídico».

Solamente una vez en el derecho comercial, dentro de un proceso ejecutivo con título hipotecario, se solicitó por una de las partes la aplicación de la excepción de inconstitucionalidad. Sucedió en la sentencia de fecha 12 de marzo de 2007, con radicado nro. 68679-3103-002-2002-00098-01, M.P. Carlos Augusto Padilla Tarazona. El motivo por el cual se ha inaplicado la excepción de inconstitucionalidad en el Tribunal Superior del Distrito Judicial en este asunto de derecho comercial es el siguiente:

- Es inconstitucional la obligación contenida en la redenominación del crédito de UPAC a UVR. Se negó con el siguiente argumentó: «La redenominación de las obligaciones pactadas en UPAC a UVR fue ordenada en forma expresa por el artículo 38 de la Ley 546 de 1999».

En la tabla 1 se clasifican las áreas del derecho, los eventos, los argumentos para solicitar la aplicación de la excepción de inconstitucionalidad y los motivos para negar la aplicación de la excepción de inconstitucionalidad.

En esta investigación se ha podido determinar que en el período 1991-2011, nunca se ha aplicado la excepción de inconstitucionalidad en el Tribunal 
Tabla 1

\begin{tabular}{|c|c|c|c|c|c|}
\hline \multirow[b]{2}{*}{ Fecha } & \multirow[b]{2}{*}{ Radicado } & \multirow{2}{*}{$\begin{array}{c}\text { Argumento para } \\
\text { solicitar la aplicación } \\
\text { de la EI } \\
\end{array}$} & \multicolumn{2}{|c|}{ ¿Aplicación? } & \multirow{2}{*}{$\begin{array}{c}\text { Argumento del juez } \\
\text { para negar la aplicación } \\
\text { de la EI }\end{array}$} \\
\hline & & & Sí & No & \\
\hline $23 / 10 / 2003$ & $\begin{array}{l}\text { 68-755-31-03- } \\
002-2002- \\
0023-01\end{array}$ & $\begin{array}{l}\text { El art. } 251 \text { del CST } \\
\text { establece el no pago de } \\
\text { cesantías a determina- } \\
\text { dos trabajadores, norma } \\
\text { que viola el derecho a la } \\
\text { igualdad. }\end{array}$ & & $\checkmark$ & $\begin{array}{l}\text { La norma no es incons- } \\
\text { titucional, en razón a } \\
\text { que el art. } 251 \text { del CST } \\
\text { dice que el artículo } 249 \\
\text { de la misma norma no } \\
\text { se aplica a los artesanos } \\
\text { que, trabajando perso- } \\
\text { nalmente en su esta- } \\
\text { blecimiento, no ocupen } \\
\text { más de cinco traba- } \\
\text { jadores permanentes } \\
\text { extraños a su familia. }\end{array}$ \\
\hline $21 / 09 / 2006$ & $\begin{array}{l}\text { 68861-3103- } \\
\text { 002-2004- } \\
00065-00\end{array}$ & $\begin{array}{l}\text { Es nula la terminación } \\
\text { de los contratos, en } \\
\text { razón a que se predica la } \\
\text { inconstitucionalidad del } \\
\text { Decreto } 1615 \text { de } 2003 \text {, ya } \\
\text { que todavía no se han } \\
\text { resuelto las demandas } \\
\text { de inconstitucionalidad } \\
\text { que cursan en el Consejo } \\
\text { de Estado contra dicha } \\
\text { norma. Por lo tanto, } \\
\text { corresponde al juez in- } \\
\text { aplicarlo por vía de } \\
\text { excepción de inconsti- } \\
\text { tucionalidad. }\end{array}$ & & $\checkmark$ & $\begin{array}{l}\text { No es viable, ya que el } \\
\text { Decreto demandado tie- } \\
\text { ne plena vigencia y se } \\
\text { encuentra revestido de } \\
\text { la presunción de legali- } \\
\text { dad, en atención a que } \\
\text { no ha sido declarado } \\
\text { nulo por la jurisdicción } \\
\text { correspondiente. }\end{array}$ \\
\hline $02 / 11 / 2008$ & $\begin{array}{l}\text { 68755-3103- } \\
\text { 002-2006- } \\
00814-01\end{array}$ & $\begin{array}{l}\text { La base de la fórmula de } \\
\text { reajuste contenida en el } \\
\text { art. } 1 \text { de la Ley 4de 1976, } \\
\text { es la que se aplica } \\
\text { actualmente a quienes se } \\
\text { pensionaron antes de la } \\
\text { entrada en vigencia de la } \\
\text { Ley } 100 \text { de } 1993 \text { y des- } \\
\text { pués de expedida aque- } \\
\text { lla. Aduce que el art. } 1^{\circ} \\
\text { de la Ley } 4^{\circ} \text { fue dero- } \\
\text { gado por la Ley } 100 \text { de } \\
\text { 1993, su texto no se ha } \\
\text { agotado y continúa } \\
\text { produciendo efectos } \\
\text { jurídicos. }\end{array}$ & & $\checkmark$ & $\begin{array}{l}\text { La acusación contra el } \\
\text { art. } 1 \text { de la Ley } 4 \text { de } 1976 \\
\text { se estructuró a partir de } \\
\text { un supuesto equivo- } \\
\text { cado toda vez que dicha } \\
\text { norma, además de en- } \\
\text { contrarse derogada táci- } \\
\text { tamente por el art. } 1 \text { de } \\
\text { la Ley } 71 \text { de } 1998 \text {, en la } \\
\text { actualidad no está pro- } \\
\text { duciendo ningún efecto } \\
\text { jurídico. }\end{array}$ \\
\hline $12 / 03 / 2007$ & $\begin{array}{l}\text { 68679-3103- } \\
002-2002- \\
00098-01\end{array}$ & $\begin{array}{l}\text { Es inconstitucional la } \\
\text { obligación contenida en } \\
\text { la redenominación del } \\
\text { crédito de UPAC a UVR. }\end{array}$ & & $\checkmark$ & $\begin{array}{l}\text { La redenominación de } \\
\text { las obligaciones pacta- } \\
\text { das en UPAC a UVR } \\
\text { fue ordenada en forma } \\
\text { expresa por el art. } 38 \text { de } \\
\text { la Ley } 546 \text { de } 1999 .\end{array}$ \\
\hline
\end{tabular}

Elaboración propia. 
Superior del Distrito Judicial de San Gil. Lo más preocupante para el sistema jurídico, es que nunca se ha aplicado por los operadores judiciales, quienes tienen a su cargo la función de impartir justicia. No se concibe cómo frente a un cúmulo de sentencias que se derivan de la defensa de garantías constitucionales y derechos fundamentales, esta figura tenga tan poca importancia.

Juan Carlos ESGUERRA PORTOCARRERO (2010, pp. 107-108) señala que la excepción de inconstitucionalidad resulta de la misma comparación de la norma inferior con la Constitución, de la cual surge una violación, no solo palmaria, si no inmediata y directa de una norma constitucional específica. Por consiguiente, se puede dar cuenta que, tanto el argumento expuesto por la parte para solicitar la excepción de inconstitucionalidad, como la razones exhibidas por los operadores judiciales del Tribunal Superior del Distrito Judicial de San Gil, carecen de manera indudable de fundamentos jurídicos propios de la figura y que si bien es cierto son situaciones que se generan en razón a la contradicción manifiesta de normas jurídicas con la Constitución «norma de normas», no se entiende a ciencia cierta cuál es el motivo generador o la esencia de esta figura en las sentencias objeto de estudio.

Juan Manuel CHARRY URUEÑA, (1994, pp. 112-116) manifiesta que, según el principio de supremacía constitucional, la Constitución es la norma fundamental que sirve de base para todo el ordenamiento jurídico. De esta manera, este principio goza de dos consecuencias: la primera la determinación de mecanismos sancionadores adecuados capases de impedir su transgresión, y la segunda la existencia de una jurisdicción especial encargada de guardar su integridad, el establecimiento de acciones para sacar del ordenamiento jurídico normas violatorias de la Constitución y la facultad de no aplicar las que le sean contrarias, lo cual garantiza que todas las demás normas se sujeten a la Constitución.

\section{CONCLUSIONES}

El control constitucional ha tenido una evolución en el devenir histórico mundial y en el latinoamericano. En este caso, se ha centrado la atención en el desarrollo jurídico e histórico que se ha tenido en Colombia. Siendo así, dicho mecanismo fue mutando y evolucionando, también tomando modelos de otros Estados y adecuados a la legislación interna de la Nación. Esto ha dado como resultado el control concentrado y el control difuso, los cuales son mecanismos muy importantes para salvaguardar la Constitución Política de derechos y hacer prevalecer sus postulados por encima de la Ley y la demás normatividad. Esto es una manifestación clara del Estado Constitucional o Estado social de derecho. 
El control judicial de constitucionalidad en Colombia es mixto por cuanto es el resultado de la influencia del control concentrado originado en Europa y del difuso, cuya génesis se encuentra en Estados Unidos. Este último puede ser ejercido por cualquier operador judicial. El control difuso de constitucionalidad es una manifestación del Estado social de derecho, en donde debe prevalecer la Constitución Política por encima de cualquier Ley o norma jurídica; por tanto, todos los jueces tienen la potestad de inaplicar una norma que vaya en contra de los postulados constitucionales.

El Acto Legislativo 03 de 1910 quizás es el antecedente más importante en lo que concierne al control de constitucionalidad, pues desarrolla el principio de supremacía constitucional; tan es así que abre paso a la excepción de inconstitucionalidad y a la acción pública de inconstitucionalidad como mecanismos idóneos y eficaces para la salvaguarda de la Constitución Política. La excepción de inconstitucionalidad toma fuerza con el pasar de los años, pues se hace más contundente su inclusión en el ordenamiento jurídico, al encontrar el control de constitucionalidad en los Actos Legislativos una manera de materializarse, ya que a través de estos se contextualiza evitando arbitrariedades al momento de su aplicación.

Un ordenamiento superior que adolezca de un eficiente sistema de control de constitucionalidad de las Leyes es un ordenamiento «herido de muerte». Por ende, la importancia de un sistema jurídico estable, coherente y respetuoso de los derechos y las garantías fundamentales no depende de la existencia o no de diversos controles sobre su producción normativa, sino del verdadero cumplimiento de sus fines como medio para garantizar la efectividad de los principios fundamentales que irradian el ordenamiento.

Se obtuvo como resultado que únicamente se hizo mención de la excepción de inconstitucionalidad tres (3) veces en procesos laborales, una (1) vez en procesos civiles y nunca se hizo mención en procesos de familia, laborales, agrarios ni penales. Sin perder de vista que en todas las situaciones fácticas se solicitó únicamente por las partes en conflicto, lo que nos permite concluir que para los operadores judiciales pasa desapercibida la excepción de inconstitucionalidad, que es ineficaz e inoperante frente al modo de resolver de los funcionarios, de tal manera que la Constitución Política siendo «norma de normas» en un Estado social de derecho, pareciera no tener relevancia.

En razón a ello, la excepción de inconstitucionalidad, aplicada con responsabilidad, hace de un Estado social de Derecho un verdadero Estado constitucional, suscitando la aplicabilidad de la teoría del control de pesos y contrapesos, para fortalecer aquel adagio popular que dice: «el poder limitar al poder». De otra parte, fortalece la importancia del ser humano en el Estado, al dar paso a la evolución de los derechos fundamentales y al principio de supremacía constitucional. 
El comportamiento omisivo, poco proactivo e infructífero de los operadores judiciales, como hipótesis, podría plantear que las dificultades para la aplicación de la excepción de inconstitucionalidad se resumen en la temeridad de los funcionarios judiciales, la inseguridad jurídica, ya que podrían acabar con el llamado «gobierno de las Leyes» y vulnerando ampliamente el derecho fundamental de la igualdad, pues no solo está el miedo para aplicar la figura, sino que existen muchos factores determinantes como el prevaricato, las investigaciones disciplinarias, entre otros.

\section{BIBLIOGRAFÍA}

Asamblea Nacional Constituyente. (1991). Constitución Política de Colombia. Bogotá D.C.: Legis.

ARAGÓN REYES, M. (1999). Constitución y control del poder. Introducción a una teoría constitucional del control. Bogotá: Universidad Externado de Colombia, 71 - 75.

BREWER-CARÍAS, A. R. (1995). El sistema mixto o integral de control de constitucionalidad en Colombia y Venezuela. Temas de Derecho Público No. 39. Instituto de Estudios Constitucionales Carlos Restrepo Piedrahita. Bogotá: Universidad Externado de Colombia.

CABALLERO PALOMINO, S. A., CRUZ CADENA, K. . Y., \& TORRES BAYONA, D. F. (2018). Derechos humanos emergentes: ¿nuevos derechos?. Advocatus, 15(30), $125-131$.

CABALLERO PALOMINO, S., CRUZ CADENA, K., \& TORRES BAYONA, D. (2018). Los derechos humanos y el desarrollo social integral en los Estados: una perspectiva frente a la paz, la economía y el gobierno. Legem, 4 (2), 65-75.

CARO, M. A. (15 de Agosto de 1887). Ley 153. Por la cual se adiciona y reforma los códigos nacionales, la ley 61 de 1886 y la 57 de 1887. Bogotá.

CHARRY URUEÑA, J. M (1994). La excepción de inconstitucionalidad. Bogotá: Jurídica Radar.

CHINCHILLA, T.E. (2010). Concepciones sobre el Juez Constitucional en la reforma de 1910: Una cuestión de confianza. Diálogos de Derecho y Política, núm. 3, año 1. Medellín: Universidad de Antioquia.

CIFUENTES MUÑOZ, E. (1997). La justicia constitucional en Colombia. Anuario Iberoamericano de Justicia Constitucional, núm. 1, enero/diciembre, pp. 67-87. 
Corte Constitucional de Colombia. Sentencia C-122 de 2011, de marzo 1.

Corte Constitucional de Colombia. Sentencia T-006 de 1994, de enero 17.

CRUZ CADENA, K. Y., CABALLERO PALOMINO, S. A., VÁSQUEZ GUALDRÓN, L., \& MORENO ORTIZ, M. (2020). Alcance del control difuso de convencionalidad en las providencias judiciales en Colombia. Advocatus, 17 (34), 37-46.

DEL ROSARIO-RODRÍGUEZ, M. F. (2011). La supremacía constitucional: naturaleza y alcances. Díkaion, año 25, 20 (1). Chía, Colombia: Universidad de la Sabana.

ESGUERRA PORTOCARRERO, J. C. (2010). La protección constitucional del ciudadano. Bogotá: Legis.

FARALLI, C. (2013). La filosofía del derecho contemporánea. Los temas y desafíos. Bogotá: Universidad Externado de Colombia.

GIRÓN REGUERA, E. (2003). El control de constitucionalidad en Colombia. En: PÉREZ ROYO, J.; URÍAS MARTÍNEZ, J. P. y CARRASCO DURÁN, M. (Eds.) Derecho Constitucional para el Siglo XXI. Tomo II. Thomson Aranzadi, Cizur Menor, 2006, pp. 3891-3913.

GONZALEZ QUINTERO, R. Ley fundamental, supremacía de la Constitución y control de constitucionalidad: una aproximación distinta a la sentencia Marbury vs. Madison, y a los orígenes de la justicia constitucional. Revista Jurídicas. Vol. VIII, núm. 2. pp. 13-29. Universidad de Caldas. Colombia.

GRANT, J.A.C. (1963). El control jurisdiccional de la constitucionalidad de las leyes. México. Revista de la Facultad de Derecho de México.

HENAO HIDRÓN, J. (2010). Derecho Procesal Constitucional. Bogotá: Temis.

HERNÁNDEZ GALINDO, J.G. El Sistema de Control de Constitucionalidad. Intervención en el Simposio Quince años de la Constitución Política. Colombia, pp. 6070. Recuperado en: http://www.juridicas.unam.mx/publica/librev/rev/juicio/ cont/4/cnt/cnt5.pdf

LANCHEROS, J. C. (2009). Del Estado Liberal al Estado Constitucional. Implicaciones en la comprensión de la dignidad humana. Díkaion, 23(18), 247-267. Chía: Universidad de la Sabana.

LASCARROCASTELLAR, C., LASCARROCASTELLAR, D., CABALLEROPALOMINO, S., (2018). Emancipación, hegemonía y autonomía relativa del derecho. Legem, 5 (1), 1-22.

LÓPEZ MEDINA, D. E. (2012). El derecho de los jueces. Bogotá: Legis. 
MAYA CHÁVES, M. J. (2012). Discordia, reforma constitucional y excepción de inconstitucionalidad. Revista de Estudios Sociales, 118-128.

MORENO ORTIZ, L. J. (2010). El sistema de control de constitucionalidad en Colombia. Civilizar Ciencias Sociales y Humanas, 10(19), 75-92.

NARANJO MESA, V. (1994). Teoría constitucional e instituciones políticas. Bogotá: Temis.

OCHOA, Y. C. (2010). El control de constitucionalidad por vía de excepción: un mecanismo que garantiza la supremacía e integridad de la Constitución. Principia Iuris, 14 (14), pp. 9-14. Tunja: Universidad Santo Tomás.

OLANO GARCÍA, H. A. (2005). Interpretación y dogmática constitucional. Bogotá: Ediciones Doctrina y Ley.

QUINCHE, M.F. (2018). Derecho constitucional colombiano. Bogotá: Temis.

RESTREPO, C. (comp.) (2005). Constituciones Politicas Nacionales de Colombia. Bogotá: Universidad Externado de Colombia.

TOBO, J. (2006). La Corte Constitucional y el control de constitucionalidad en Colombia. Bogotá: Ediciones Jurídicas Gustavo Ibáñez.

TORRES BAYONA, D. (2012). Propuesta: Aplicación de la excepción de inconstitucionalidad en Colombia: estudio de caso del Tribunal Superior del Distrito Judicial de San Gil, entre los años 1991 y 2011. Socorro: Universidad Libre. Documento sin publicar.

TORRES BAYONA, D. (2013). Modelos de justicia y control constitucional: comparación diacrónica y sincrónica. El Centauro, pp. 55-62. Socorro: Universidad Libre.

VILA CASADO, I. A. (2007). Fundamentos del derecho constitucional contemporáneo. Bogotá: Legis.

VILLANUEVA GARZON F. A., VACA AMÉZQUITA, J.S., CABALLERO PALOMINO S.A. (2021) Protección Constitucional del Derecho de Habeas Data. Reportes negativos en Centrales de Riesgo. Bogotá D.C.: Ibáñez.

ZAMBRANO GARRIDO, D. A. (2011). La Excepción de inconstitucionalidad (18861991). Boletín No. 28 del Instituto de Estudios Constitucionales, pp. 115-131. Bogotá: Universidad Sergio Arboleda.

ZULUAGA, R. (2003). El carácter integral, complejo y abierto del sistema colombiano de control de constitucionalidad. Criterio Jurídico (3), pp. 152-173. Cali: Universidad Javeriana. 